УДК 633-156.39, DOI 10.31210/visnyk2018.02.26

(C) 2018

\author{
Арендаренко В. М., кандидат технічних наук, \\ Самойленко Т. В., здобувач
}

Полтавська державна аграрна академія

\title{
МАТЕМАТИЧНЕ МОДЕЛЮВАННЯ ПРОЦЕСУ ЗАВАНТАЖЕННЯ СИЛОСІВ ЗЕРНОМ
}

\section{Рецензент - кандидат технічних наук Р. М. Харак}

Технологічний проиес завантаження силосів зерном передбачає підйом зерна на певну висоту, потім транспортування його до завантажувального отвору ємності. В иьому проиесі використовуються ковшові елеватори, скребкові та самопливні транспортери та спеціальні завантажувальні пристрої силосів. На всіх етапах транспортування зернової маси відбувається травмування зернівок, щчо негативно впливає на прочес їх зберігання. На травмування зернівок впливають зовнішні та внутрішні фактори, притаманні окремим транспортним машинам: фізико-механічні та біологічні властивості зерна (внутрішні фактори), конструктивні та технологічні параметри машин, які використовуються для завантаження силосів зерном (зовнішні фактори).

Запропоновано математичну модель усього технологічного процесу завантаження ииліндричних смностей зерновим матеріалом. Найбільш вдалими методами обтрунтування такої моделі є методи імітаційного моделювання. Створена на основі імітації параметрична модель враховує окремі елементи множин, які відповідають ковшовим елеваторам, скребковим транспортерам та завантажувальним пристроям силосів. Із розробленої моделі випливає, щ⿻о основною задачею $є$ вірний підбір параметрів, котрі впливають на завантаження силосів зерном, щуо, в свою чергу, зменшує травмування, часткове пошкодження та повне руйнування зернівки.

Ключові слова: зерно, силос, ємність, транспортування, параметри, проиес, завантаження, травмування.

Постановка проблеми. Завантаження силосів зерновим матеріалом відбувається за допомогою ковшових, скребкових та самопливних транспортерів. Таке завантаження призводить до травмування частини зерна $[1-4,6]$. Також зерно травмується, вдаряючись об стінки та дно силосу. Щоб ефективно керувати завантажувальною системою зерносховища, слід розробити математичну модель, яка б враховувала всі зовнішні і внутрішні фактори цієї системи, котрі впливають на процес травмування зерна.

Аналіз останніх досліджень і публікацій, у яких започатковано розв'язання проблеми. На стабільність функціонування ємностей для зберігання зерна типу силос впливають певні внутрішні і зовнішні фактори. Вченими [7, 8], використовуючи математичний апарат, розроблено моделі функціонування окремих транспортних систем (ковшових елеваторів, скребкових i самопливних транспортерів) та ємностей для зберігання зернового матеріалу. В цих математичних моделях у певній мірі враховуються фізико-механічні i біологічні властивості зерна (внутрішні фактори), конструктивно-технологічні параметри транспортерів і ємностей (зовнішні фактори).

Мета досліджень - розробка математичної моделі функціонування всієї системи завантаження силосів зерном на зернозберігаючих підприємствах.

Матеріали і методи досліджень. Дослідження процесу завантаження силосів зерном виконувалися 3 використанням методів класичної кваліметрії та задач лінійної алгебри.

Результати досліджень. Процес завантаження силосів зерном складається 3 трьох етапів: на першому етапі відбувається підйом зернового матеріалу на певну висоту; на другому етапі зерновий матеріал скребковим транспортером подається до завантажувальної горловини силосу, а на третьому етапі ємність завантажується сипким вантажем. Наочне зображення функціонування такої системи дає параметрична модель. Вона дає змогу розглянути всі фактори, котрі впливають на процес завантаження силоса.

Позначимо три взаємопов'язані процеси наступним чином: підйом вантажу на певну висоту (ППЗ), транспортування вантажу по горизонтальним галереям (ПТЗ), завантаження вантажу в ємність (ПЗС). На кожному етапі на процес транспортування та травмування окремих частинок вантажу (аж до завантаження його в ємність) впливають зовнішні та внутрішні фактори. До зовнішніх факторів слід віднести геометричні та кінематичні параметри транспортерів, параметри завантажувальних та перевантажувальних пристроїв, фізико-механічні властивості зернового матеріалу та наслідки попередніх етапів цього 


\section{TEХНIЧНI НАУКИ}

технологічного процесу. Вплив зовнішніх факторів на кожному етапі представимо у вигляді функції, аргументами якої будуть фактори, що характеризують травмування, пошкодження або повне руйнування зернівок.

Графічно параметрична модель функціонування транспортно-завантажувальної системи представлена на рис. 1 .

Процес функціонування вище вказаної системи характеризується такими функціоналами: $\bar{X}_{П П \Pi 3}, \bar{X}_{\text {ПТз }}, \bar{X}_{\Pi \text { ПЗ }}$,

де $\bar{X}_{\text {Ппз }}$ описує умову вертикального підйому зернового матеріалу (сюди входять параметри ковшів норійних елеваторів, швидкість транспортування, фізико-механічні властивості зернового матеріалу), $\bar{V}_{\text {ппз }}$ виражає вплив вертикального підйому зернової маси на стан зерна, $\bar{X}_{\text {Птз }}$ описує процес транспортування зернового матеріалу горизонтальними скребковими транспортерами (конструкція горизонтальної галереї, геометричні параметри скребкового транспортера, кінематичні параметри, властивості зерна), $\bar{Y}_{\text {Птз }}$ показує результат транспортування на процес подачі сипучої маси зерна, $\bar{X}_{\text {пзс }}$ характеризує умову завантаження силосу (параметри завантажувального пристрою, фізико-механічні властивості зернового матеріалу), $\bar{y}_{\Pi з C}$ описує вихідні параметри завантаження силосу:

$$
\begin{aligned}
& \bar{X}_{\Pi 3 C}=\bar{X}_{\Pi 3 C}\left(x_{13 C}^{\prime \prime}, \ldots, x_{n 33}^{\prime \prime}\right), \\
& \bar{y}_{\Pi 3 C}=\bar{y}_{\Pi 3 C}\left(y_{13 C}^{\prime \prime}, \ldots, y_{n 33}^{\prime \prime}\right) .
\end{aligned}
$$

На процес травмування, пошкодження або повне руйнування зернівок під час їх транспортування і завантаження в силоси впливають:
- геометричні параметри транспортних і завантажувальних пристроїв;

- кінематичні параметри транспортних пристроїв;

- фізико-механічні властивості зернового матеріалу.

У дослідженнях ці параметри можна використовувати як для порівняння різних способів транспортно-завантажувальних процесів і пристроїв, так і для окремого пристрою. Для ковшового транспортера факторами, що впливають на цілісність зернівок під час їх транспортування, будуть:

$x_{1 n}-$ геометричні параметри ковша;

$x_{2 n}-$ геометричні параметри головки норії $\mathrm{i}$ випускного пристрою;

$x_{3 n}$ - заповнення ковша зерном;

$x_{4 n}$ - швидкість пересування ковшів;

$x_{5 n}-$ зворотне зсипання зернівок;

$x_{6 n}-$ тип завантаження;

$x_{7 n}$ - фізико-механічні властивості зерна;

$x_{8 n}-$ стискання та защемлення зернівок.

Травмування зерна в ковшових транспортерах відбувається внаслідок отриманого ним імпульсу від різниці векторів напрямків кінетичної енергії зерна і норійних ковшів у випадку їх зіткнення. На рис. 2 представлена схема впливу кінетичних i геометричних параметрів норій на травмування зернівок.

Ковшові елеватори (норіï) характеризуються розмірами, тому в кінематичній моделі використовується обмеження типу $k<x_{1}<n$. Поряд із обмеженням на периметр може бути і обмеження на висоту норії. Ці обмеження є технологічними і залежать від конструкцій елеватора.

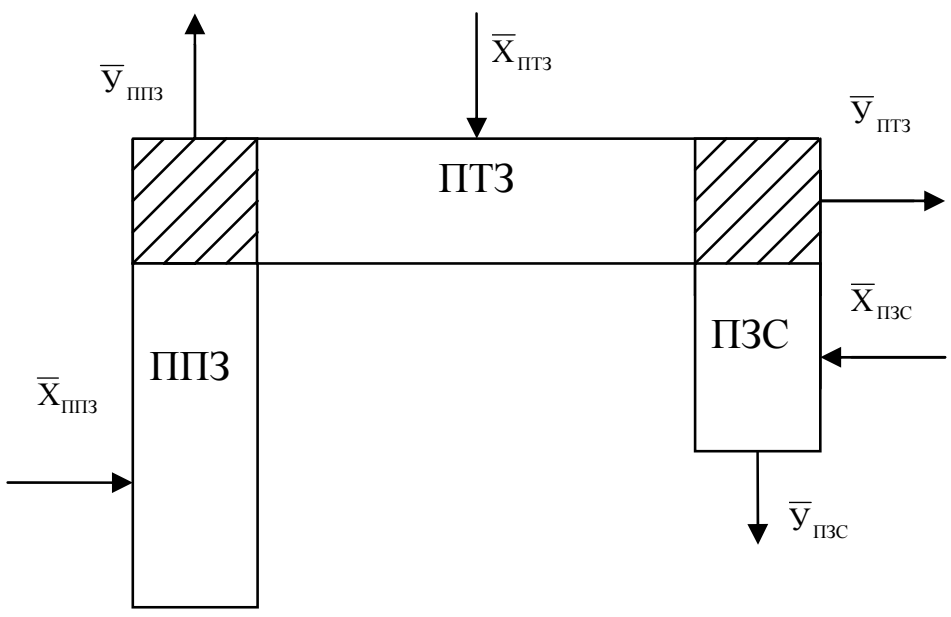

Рис. 1. Параметрична модель функціонування транспортно-завантажсувальної системи 


\section{TEХНІЧНI НАУКИ}

У випадку зміни конструктивних параметрів $x_{1 n}, x_{2 n}, x_{3 n}$ відбувається зміна кінематичного параметра $x_{4 n}$, що зменшує ударні сили, а значить i травмування зерна. Процес підйому зернової маси норійними ковшами описується векторною функцією:

$$
\begin{aligned}
& f\left(x_{1}, \ldots, x_{n}\right)=\left(y_{1}, \ldots, y_{k}\right), \\
& \text { де } \\
& y_{i}=y_{i}\left(x_{1}, \ldots, x_{k}\right), i=1, \ldots, k
\end{aligned}
$$

Параметр $y_{i}$ характеризує місце розвантаження зернової маси і може залежати не від усього набору зовнішніх факторів $\left(x_{1}, \ldots, x_{n}\right)$, а тільки від декількох.

Вихідні параметри щодо підйому зернового вантажу $\left(y_{1}, \ldots, y_{k}\right)$ можна представити множиною $y_{1} \in R^{k}$. Виходячи із цього, бачимо, що початкові параметри діють певним чином на вихідний параметр, тобто:

$$
R^{n} \stackrel{f}{\longrightarrow} R^{k}
$$

Після вертикального підйому зернового матеріалу подальше транспортування зерна відбувається в горизонтальних коробах скребковими конвеєрами. Скребкові конвеєри 3 точки зору надійності і техніко-технологічних параметрів $\epsilon$ найбільш прийнятними для елеваторної промисловості. Переваги їх очевидні, але вони мають $\mathrm{i}$ свої недоліки. Основним недоліком є підвищене травмування, пошкодження та подрібнення зернівок.

До зовнішніх параметрів, які впливають на показники травмування, належать:

$x_{1}^{\prime}$ - геометричні параметри короба конвеєра;

$x_{2}^{\prime}$ - наявність прямого контакту тягового органу з корпусними деталями короба; $x_{3}^{\prime}$ - матеріал, 3 якого виготовлені скребки;

$x_{4}^{\prime}$ - швидкість транспортування зерна;

$x_{5}^{\prime}-$ наявність приводних зірочок і тягового ланцюга.

Процес транспортування описується дією зовнішніх параметрів $\left(x_{1}^{\prime}, \ldots, x_{m}^{\prime}\right)$, або множиною цих параметрів $x_{i} \in R^{m}$. Це означає, що на процес транспортування скребковими транспортерами зернового матеріалу впливають зовнішні параметри множин $R^{k} 4 R^{m}$. Тоді процес горизонтального транспортування описується:

$$
\begin{aligned}
& p\left(y_{1}, \ldots, y_{k}, x_{1}^{\prime}, \ldots, x_{m}^{\prime}\right)=\left(\omega_{1}, \ldots, \omega_{l}\right) . \\
& \omega_{i}=\omega_{i}\left(y_{1}, \ldots, y_{k}, x_{1}^{\prime}, \ldots, y_{m}^{\prime}\right), \omega_{i} \in R^{l}
\end{aligned}
$$

Транспортування зернової маси до завантажувального пристрою силосу можна представити за допомогою вихідних параметрів транспортної технологічної лінії:

$$
R^{k} \times R^{m} \stackrel{p}{\longrightarrow} R^{l}
$$

На процес завантаження силосу зерном та його травмування впливають свої зовнішні фактори, які описуються елементами множини $\left(x_{1}^{\prime \prime}, \ldots, x_{g}^{\prime \prime}\right)$, або $x_{i}^{\prime \prime} \in R^{g}$.

Для досліджуваних завантажувальних пристроїв силосів зовнішніми факторами є:

$x_{1}^{\prime \prime}$ - геометричні параметри пристрою,

$x_{2}{ }_{2}-$ продуктивність пристрою,

$x_{3}{ }_{3}$ - розмір випускного отвору,

$x^{\prime \prime}{ }_{4}$ - кут внутрішнього тертя вантажу,

$x^{\prime \prime}{ }_{5}$ - кут тертя між вантажем і матеріалом пристрою,

$x_{6}^{\prime \prime}$ - швидкість витання та коефіцієнт парусності.

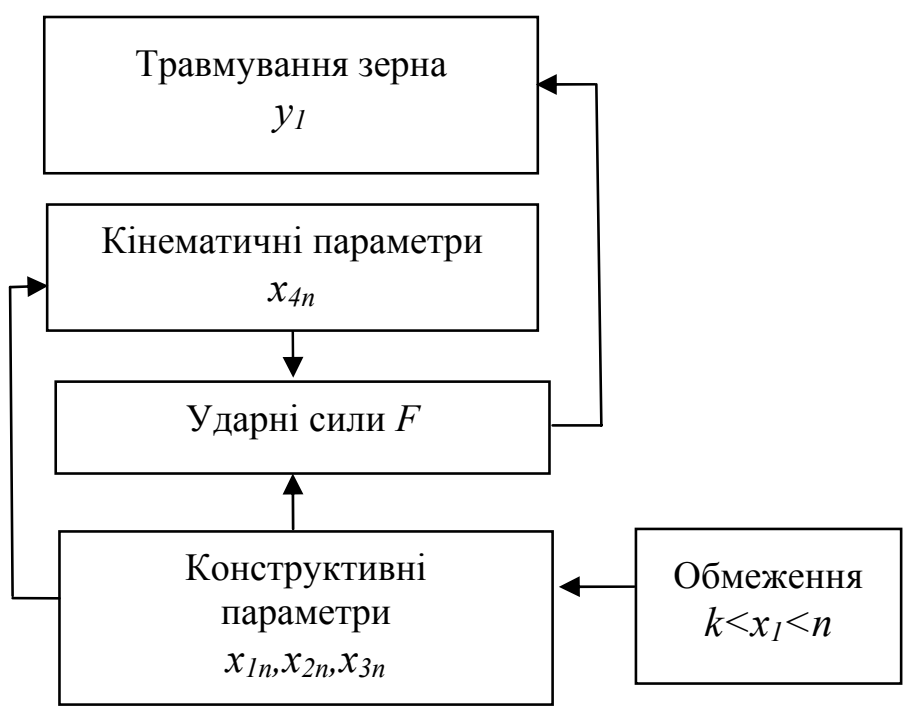

Рис. 2. Схема впливу кінематичних і геометричних параметрів на травмування зернівок у ковшових транспортерах 


\section{TEХНІЧНI НАУКИ}

Функція, яка описує процес завантаження циліндричної ємності зерном та можливість його травмування, має вигляд:

$$
h\left(\omega_{1}, \ldots, \omega_{l}, x_{1}^{\prime \prime}, \ldots, x_{g}^{\prime \prime}\right)=K_{T},
$$

де $K_{T}$ - вихідний параметр, за яким оцінюється ступінь (коефіцієнт) травмування зерна.

Таким чином, дія зовнішніх і внутрішніх параметрів буде:

$R^{l} \times R^{g} \stackrel{h}{\longrightarrow} R$,

де $R$ - простір розмірності одиниці.

Якщо всі зовнішні параметри, які впливають на процес транспортування і завантаження сило-

\section{БІБЛІОГРАФІЯ}

1. Дерев'янко Д. А. Транспортні та транспортно-технологічні процеси та обладнання // Техніка, енергетика, транспорт АПК. - №3 (92). 2015. - C. 73-78.

2. Панов A. A. Травмирование семян в результате трения // Механизация и электрификация сельского хазяйства. - 1980. - №11. - С. 18-19.

3. Травмирование семян и его предупреждение / И. Г. Строна, А. П. Пугачев и др. - М. : Колос, 1972. -152 с.

4. Олексієнко B. О. Проблеми травмування зерна при переміщенні і завантаженні його в силоси та пропозиції щодо його зниження // Праці Таврійського державного агротехнологічного університету. - 2014. - Вип. 14, т. 1. - С. 20-23.

5. Шатохин И. В. Пути снижения травмиро-

\section{ANNOTATION}

Arendarenko V. M., Samoilenko T. V. The mathematical modeling of the loading process of grain to the silos.

The technological loading process of grain to the silos is based on the lift of grain at a certain height and transportation of grain to the container's load hole. The centrifugal bucket elevators, the drag and self-flowing conveyors, the special loading devices of silos are used in this process. During all stages of this grain mass' transportation the corn seeds are traumatized. It has negative effect on the process of grain storage.

The damage of corn seeds have been influenced by the outside and inside factors connected with the certain transport machines. The physical-mechanical and biological properties of grain are inside factors. The constructional and engineering data of ma- сів зерном, винести на початок технологічного процесу, то математична модель цієї системи буде:

$$
\begin{aligned}
& R^{N} \stackrel{f}{\longrightarrow} R^{M} \stackrel{P}{\longrightarrow} R^{L} \stackrel{\mathrm{h}}{\longrightarrow} R, \\
& \text { де } N \neq n, M \neq m, L \neq l .
\end{aligned}
$$

Висновок. Таким чином, які б не були функції $\check{r}, q, h$, їх числове подання завжди виконується, але основним завданням є вірний підбір параметрів, котрі впливають на досліджуваний процес завантаження силосів зерном i зменшення травмування, пошкодження та руйнування зернівок.

вания зерна при перегрузке его нориями (зерноочистительных линий) // Сб. науч. тр. Воронежского СХИ. - 1985. - С. 65-75.

6. Тарасенко A. П. Снижение травмирования зерна. - М. : Россельхозиздат, 1980. - 30 с.

7. Бедич T. В. Обоснование скорости движения ленты ковшового элеватора, направленное на снижение травмирования зерна : автореф. дис. на соискание учен. степени канд. техн. наук : спец. 05.20.01 «Технологии и средства механизации сельского хозяйства». - Оренбург, 2009. $21 \mathrm{c}$.

8. Зуев Ф. А. Подъемно-транспортные машины зерноперерабатывающих предприятий. - М.: Агропромиздат, $1985 .-320 \mathrm{c}$.

chines, which we use for the loading process of grain to the silos, are outside factors.

The mathematical modeling of all engineering loading process of grain material to the silos has been suggested in this article. The most successful methods of study of this model are the methods of simulation modeling. The parametric model, created on the basis of simulation, takes account of the certain set members, which conform to the centrifugal bucket elevators, the drag conveyors and the loading devices of silos. It follows from this engineered model that the main problem is a correct selection of the parameters influencing on the loading process of grain to the silos. It will lead to decrease the partial and complete destruction of the corn seeds.

Keywords: grain, silos, corn seed, data, loading process, mathematical modeling, trauma. 